\title{
Управление инновациями
}

УдК 33

ГИЧИЕВ НАБИЮЛА САПИЮЛАЕВИЧ

к.э.н., ведущий научный сотрудник, заведующий отделом теории и методологии регионального развития, Институт соииально-экономических исследований ДФИЦ $\rho$ АН

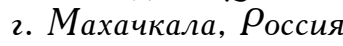
e-mail: nabi-05@mail.ru

\section{DOI:10.26726/1812-7096-2021-8-64-71 \\ ИНВЕСТИЦИИ В ИННОВАЦИИ И ЭКОНОМИЧЕСКИЙ РОСТ: РЕГРЕССИОННАЯ МОАЕАЬ}

\begin{abstract}
Аннотауия. Целью исследования является изучение влияния инноваций на экономический рост Северо-Кавказского макрорегиона. Предметом исследования являются проиессы взаимодействия инновационных факторов с динамикой валового регионального продукта регионов Северо-Кавказского федерального округа. Методология. Применяется статистический метод коррелящионно-регрессионного анализа, позволяющий установить статистически значимую связь между релевантными параметрами. Ревультат и область применения. Полученные результаты исследования могут быть востребованы со стороны научных работников и практиков, занимающихся вопросами повышения эффективности инновационного процесса на субфедеральном уровне. Выводы/значимость. Согласно полученной спецификации наиболее важным индикатором, определяющии уровень технологического лидерства региона, является численность персонала, занятого научными исследованиями и разработками.
\end{abstract}

КАючевые слова: экономический рост, инвестииии, инноваиии, технический прогресс, производственные технологии, регион, эконометрическая модель.

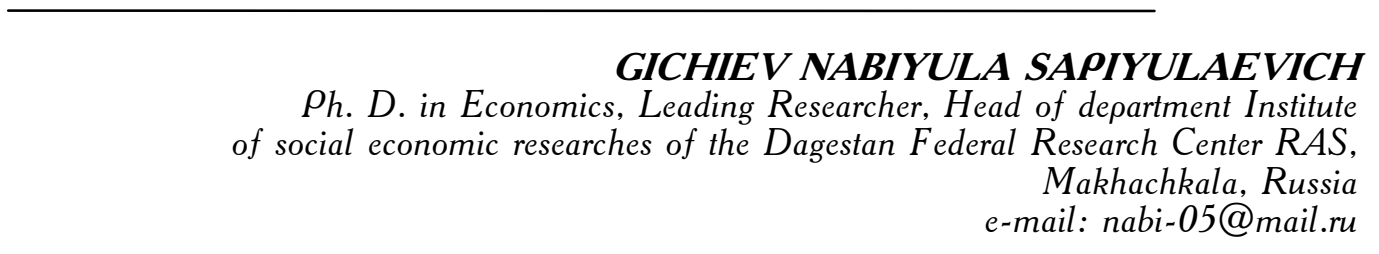

\section{INVESTMENT IN INNOVATION AND ECONOMIC GROWTH: REGRESSION MODEL}

Abstract. The aim of the study is to study the impact of innovation on the economic growth of the North Caucasus macroregion. The subject of the research is the processes of interaction of innovative factors with the dynamics of the gross regional product of the regions of the North Caucasian Federal District. Methodology. The statistical method of correlation-regression analysis is used, which allows to establish a statistically significant relationship between the relevant parameters. Result and scope. The obtained results of the research can be in demand on the part of scientific workers and practitioners dealing with the issues of increasing the efficiency of the innovation process at the subfederal level. Conclusions / Relevance. According to the obtained specification, the most important indicator that determines the level of technological leadership in a region is the number of personnel engaged in research and development.

Keywords: economic growth, investment, innovation, technical progress, production technologies, region, econometric model. 
1. Введение. Важность технического прогресса в стимулировании экономического роста широко освещается в научной литературе, посвященной пониманию инноваций, посредством которых открываются и внедряются новые технологии, повышающие общую производительность экономики. Хотя исследования и разработки, безусловно, являются важным компонентом инновационного процесса, многие авторы подчеркивали, что эти две концепции не эквивалентны.

Baldwin et al. [3], Kamin et al.[12, c.83-94] идентифицируют такие виды деятельности, как исследования, разработка и проектирование продукта, спецификация продукта, создание прототипа, запуск производства и организационные изменения; все виды деятельности, которые обычно не классифицируются как НИОКР, но имеют решающее значение для внедрения новой технологии в производство. Baldwin и др. [3] утверждают, что НИОКР являются лишь частью инноваций. Согласно официальному определению ОЭСР, НИОКР отличаются от других затрат на инновации и должны иметь «заметный элемент новизны и решение научных задач». В тоже время по методологии ОЭСР НИОКР исключает такие важные элементы инновационного процесса, как затраты на проектирование и разработку и другие расходы на реализацию.

В рамках данного исследования различные аспекты инноваций и НИОКР представляют научный интерес с точки зрения их влияния на экономический рост региона.

1. Теория и методология исследования. Производительность труда, человеческий и физический капитал, нормы сбережений, рост рынка и технологии входят в число факторов, которые считаются важными для объяснения экономического роста Базовая неоклассическая производственная функция предсказывает, что экономический выпуск является функцией капитальных и трудовых затрат [4]. А. Смит, в книге «Богатство наций» [17], описал, как эти затраты влияют на рост в обрабатывающей промышленности и сельском хозяйстве.

В своей книге «Капитализм, социализм и демократия» [16] Й. Шумпетер внедрил инновации в качестве стимула устойчивого роста. Й. Шумпетер подчеркнул, что фундаментальным импульсом, поддерживающим движение капиталистического двигателя, были новые товары, новые методы производства, новые рынки и новые формы организации производства.

К 1950-м годам результаты научных исследований по оценке взаимосвязи затрат и выпуска показали, что большая часть роста выпуска на душу населения генерировалась необъясненными капитальными и трудовыми затратами. Необъясненный «остаток» был обозначен М. Абрамовицем [1, с. 5-23] как «мера нашего невежества». Дальнейшие исследования сократили данный пробел, но технический прогресс и инновации остались необъяснённым фактором роста производительности экономики [2, с. 217-243].

П. Ромер был одним из первых, кто включил технологию, наряду с капиталом и трудом, в производственную функцию экономического роста [14, с. 1002-1037, 15, с. 71 - 102]. П. Ромер расширил теоретическую модель Р. Солоу [19, с. 312-320], включавшей технологии в общественное благо, одинаково доступное для всех фирм. В модели экономического роста П. Ромер ставит технологии под контроль отдельных фирм, отсюда и появился термин «эндогенная модель роста».

Эндогенные переменные объясняются или предсказываются в рамках теоретической модели, тогда как предполагается, что экзогенные переменные определены заранее или зафиксированы относительно эндогенных переменных. Модель Р. Солоу рассматривает технологии как экзогенную переменную, влияющую на производство за счет эндогенного капитала и затрат труда. В тоже время модель П. Ромера рассматривает производство технологий в качестве эндогенной переменной наряду с капитальными и трудовыми затратами. П. Ромер разработал дополнительную математическую модель для объяснения производственной технологии, основанной на затратах капитала и труда.

Многие исследования взаимосвязи НИОКР с экономическим ростом и внедрением технологий проводились на основе отраслевых данных [5]. Так Hill [9] использовал региональные данные, чтобы продемонстрировать взаимосвязь между расходами на НИОКР и производительностью в отраслях, связанных с производством промышленного оборудования. Данные исследования подтверждают, что преимущества НИОКР оцениваются в уровне их коммерциализации, увеличении объемов производства, росте занятости и производительности труда.

Ц. Грилихес [8, с.1661-1707] предложил исследовать корреляции между количеством 
патентов, расходов на НИОКР с показателями выпуска. В дальнейшем Ц. Грилихес [7, с. 84. 1-23] отметил, что общее количество патентов стало снижаться, начиная с 1970-х годов, а доля НИОКР в валовом национальном продукте (ВНП), повторило эту тенденцию в 1960-х годах. В исследовании Э. Денисона [6] сделан вывод о повышении производительности за счет снижения затрат и улучшения производственных процессов.

Эмпирические данные свидетельствуют о том, что промышленные НИОКР повышают экономический результат [5; 13, с.55]. Р. Солоу [18, с. 65-94], оценил экономический выпуск на основе эконометрической модели, в которой производство является функцией капитальных и трудовых затрат. При этом уровень технологий, расходы на НИОКР, влияющие на эту функцию, используются в качестве меры технологии.

В модели Р. Солоу [19, с. 312-320] технология определялась как внешняя сила, стимулирующая выпуск за счет повышения качества и эффективности производственного процесса. «Рост доходов на душу населения в этих моделях - это технический прогресс» [10, pp. 3334].

Сравнительный анализ социально-экономического положения и определение долгосрочных стратегических приоритетов устойчивого развития Северо-Кавказского федерального округа и входящих в него субъектов Российской Федерации представлен в работе Ахмедуева А.Ш. [20, с. 14-29].

С позиций системного подхода рассмотрены теоретико-методологические основы формирования и реализации стратегии регионального развития в условиях модернизации и инновационных преобразований экономики применительно к особенностям и условиям проблемных регионов на примере Республики Дагестан в монографии коллектива авторов [24, 302 c.].

Исследование современного состояния промышленности региона и определение основных проблем ее становления и развития рассматриваются в статье Кутаева Ш.К. и Сагидова Ю.Н. [23, c. 62-66].

Вопросы формирования нового этапа экономического роста Северо-Кавказского макрорегиона в условиях нарастания неопределенности влияния внешних и внутренних факторов его социально-экономического развития, а также исследование воздействия внешних факторов (валютного курса и внешней торговли) на экономический рост Северо-Кавказского федерального округа и краткосрочный прогноз его экономического роста с теоретических и эмпирических позиций рассмотрены в ряде научных публикаций [21, с. 177-188; 22, с. 259272].

Многие модели начинаются с производственной функции Кобба-Дугласа, а затем добавляют репрезентации нюансов отношений капитала и труда. В нашем анализе производственная функция Кобба-Дугласа применяется к агрегированным экономическим данным. Производственная функция Кобба-Дугласа описывает самые основные элементы производства в виде математической функции

$\mathrm{Y}=\mathrm{f}(\mathrm{K}, \mathrm{L})$.

где $\mathrm{Y}$ - объем производства, K - капитал, L - труд.

Методология эконометрического моделирования влияния инноваций на экономический рост представлена на рисунке 1. 


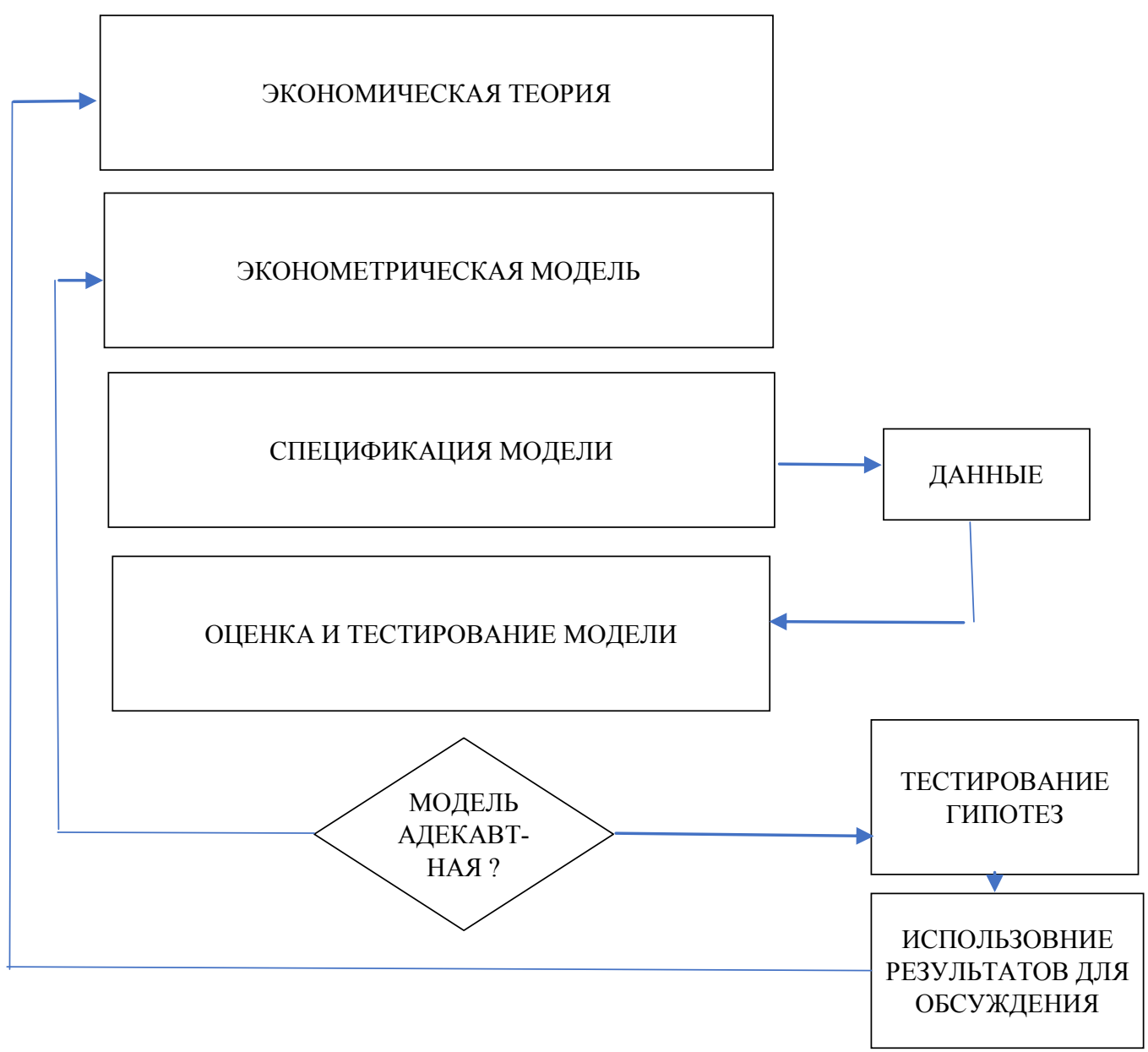

Рис. 1. Алгоритм эконометрического моделирования

3. Основная часть. Источником данных для статистического анализа стали сборники «Регионы России», выпускаемые Федеральной службой государственной статистики РФ [26]. -5 .

Перечень отобранных индикаторов инновационной деятельности представлен в таблицах 1

Таблица 1

\begin{tabular}{|c|l|c|}
\hline \multicolumn{1}{|c|}{ Показатель } & Обозначение \\
\hline \multicolumn{1}{|c|}{ Зависимая переменная } & 2 \\
\hline \multicolumn{2}{|c|}{ Независимые переменные } & $\mathrm{Y}$ \\
\hline 1 & Валовый региональный продукт & $\mathrm{X}_{1}$ \\
\hline 2 & Число организаций, выполнявших исследования и разработки, ед. & $\mathrm{X}_{2}$ \\
\hline 3 & Затраты на технологические инновации, млн. руб. & $\mathrm{X}_{3}$ \\
\hline 4 & Численность персонала, занятого научными исследованиями и разработками (человек) & \multicolumn{1}{|c|}{} \\
\hline
\end{tabular}

Согласно статистическим оценкам динамики роста числа организаций, выполнявших исследования и разработки, СКФО опережает ЮФО примерно в 2 раза $(201,4$ \% и 117,8 \% соответственно). С нашей точки зрения, такая динамика объясняется относительно низкими стартовыми значениями данного показателя в СКФО (см. таблицу 2). 
ГИЧиЕВ Н.С.

ИНВЕСТИЦИИ В ИННОВАЦИИ И ЭКОНОМИЧЕСКИЙ РОСТ: РЕГРЕССИОННАЯ МОДЕЛЬ

Таблица 2

Число организаций, выполнявших исследования и разработки

\begin{tabular}{|l|c|c|c|c|c|c|c|c|c|c|c|c|c|}
\hline & 2000 & 2005 & 2010 & 2011 & 2012 & 2013 & 2014 & 2015 & 2016 & 2017 & 2018 & 2019 & $2019 / 2000, \%$ \\
\hline ЮФО & 269 & 239 & 231 & 255 & 222 & 234 & 256 & 337 & 306 & 302 & 297 & 317 & 117,8 \\
\hline РА & 3 & 3 & 6 & 8 & 8 & 9 & 10 & 12 & 10 & 10 & 10 & 10 & 333,3 \\
\hline РК & 9 & 8 & 7 & 7 & 6 & 6 & 6 & 6 & 6 & 6 & 6 & 6 & 66,7 \\
\hline РК$^{*}$ & 0 & 0 & 0 & 0 & 0 & 0 & 15 & 23 & 21 & 20 & 20 & 24 & - \\
\hline КК & 62 & 62 & 53 & 53 & 52 & 56 & 66 & 106 & 105 & 100 & 100 & 106 & 170,9 \\
\hline АО & 20 & 21 & 23 & 36 & 17 & 20 & 20 & 25 & 24 & 24 & 23 & 25 & 125,0 \\
\hline ВО & 63 & 45 & 42 & 42 & 38 & 45 & 47 & 53 & 46 & 44 & 43 & 43 & 62,3 \\
\hline РО & 111 & 100 & 100 & 109 & 101 & 98 & 87 & 100 & 86 & 89 & 86 & 94 & 84,7 \\
\hline г. СВС & 0 & 0 & 0 & 0 & 0 & 0 & 5 & 12 & 8 & 9 & 9 & 9 & - \\
\hline СКФО & 74 & 71 & 92 & 105 & 99 & 116 & 117 & 162 & 160 & 160 & 153 & 149 & 201,4 \\
\hline РД & 22 & 22 & 29 & 29 & 28 & 30 & 30 & 41 & 45 & 45 & 40 & 38 & 172,7 \\
\hline РИ & - & 1 & 4 & 4 & 4 & 4 & 4 & 6 & 7 & 7 & 6 & 6 & - \\
\hline КБР & 15 & 12 & 14 & 14 & 14 & 14 & 14 & 20 & 18 & 19 & 17 & 18 & 120,0 \\
\hline КЧР & 4 & 5 & 6 & 5 & 5 & 7 & 8 & 11 & 11 & 10 & 10 & 11 & 275,5 \\
\hline РСО & 9 & 12 & 15 & 17 & 16 & 17 & 18 & 24 & 22 & 21 & 18 & 19 & 211,1 \\
\hline ЧР & - & 5 & 8 & 8 & 9 & 9 & 8 & 8 & 8 & 8 & 8 & 8 & - \\
\hline
\end{tabular}

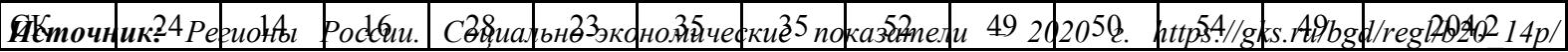
Main.htm

Примечание: $Р K^{*}$ - Республика Крым; $C B C-$ 2. Севастополь

В течение 2000-2019 гг. темпы роста затрат на технологические инновации в СКФО (1701 \%) превышали данный показатель в ЮФО (1219 \%). Помимо низкого старта объяснением данного феномена может служить разработка и реализация эффективной инвестиционноинновационной политики макрорегиона (см. таблицу 3 ).

Таблица 3

\begin{tabular}{|l|c|c|c|c|c|c|c|c|c|c|c|c|c|}
\hline & 2000 & 2005 & 2010 & 2011 & 2012 & 2013 & 2014 & 2015 & 2016 & 2017 & 2018 & 2019 & $\begin{array}{c}2019 / \\
2000, \%\end{array}$ \\
\hline ЮФО & 2392 & 6756 & 13027 & 15906 & 18618 & 19987 & 30054 & 26619 & 25797 & 25232 & 25983 & 29163 & 1219,2 \\
\hline РА & 10 & 17 & 60 & 152 & 162 & 170 & 206 & 202 & 225 & 241 & 251 & 207 & 2020,5 \\
\hline РК & 6 & 23 & 63 & 81 & 77 & 68 & 76 & 75 & 72 & 68 & 78 & 91 & 1444,0 \\
\hline РК* & 0 & 0 & 0 & 0 & 0 & 0 & 512 & 1236 & 1411 & 1488 & 1503 & 1413 & 0,0 \\
\hline КК & 699 & 1726 & 3260 & 3827 & 4818 & 4669 & 5597 & 6792 & 5866 & 5422 & 6324 & 5772 & 825,5 \\
\hline АО & 170 & 396 & 370 & 612 & 573 & 569 & 550 & 563 & 459 & 549 & 516 & 810 & 477,7 \\
\hline ВО & 331 & 738 & 2607 & 3230 & 3670 & 5294 & 8124 & 3418 & 3448 & 3548 & 3541 & 3728 & 1125,5 \\
\hline РО & 1176 & 3856 & 6668 & 8005 & 9320 & 9216 & 14723 & 13682 & 13664 & 13102 & 12944 & 15961 & 1357,7 \\
\hline г. СВС & 0 & 0 & 0 & 0 & 0 & 0 & 267 & 650 & 653 & 814 & 826 & 1182 & 0,0 \\
\hline СКФО & 311 & 944 & 2640 & 4018 & 3448 & 3696 & 4197 & 4292 & 4397 & 4609 & 5246 & 5291 & 1701,3 \\
\hline РД & 75 & 205 & 674 & 773 & 872 & 894 & 972 & 970 & 930 & 914 & 1207 & 1040 & 1389,6 \\
\hline РИ & 0 & 4 & 19 & 29 & 41 & 43 & 48 & 78 & 69 & 62 & 104 & 108 & 0,0 \\
\hline КБР & 34 & 200 & 436 & 485 & 553 & 553 & 607 & 490 & 502 & 655 & 711 & 867 & 2581,9 \\
\hline КЧР & 38 & 128 & 269 & 310 & 368 & 331 & 404 & 603 & 492 & 510 & 517 & 515 & 1357,1 \\
\hline РСО & 30 & 68 & 232 & 293 & 347 & 373 & 471 & 395 & 371 & 343 & 339 & 415 & 1393,0 \\
\hline ЧР & 0 & 15 & 111 & 121 & 139 & 272 & 344 & 286 & 218 & 269 & 279 & 350 & 0,0 \\
\hline СК & 134 & 324 & 900 & 2007 & 1128 & 1231 & 1352 & 1472 & 1815 & 1855 & 2090 & 1996 & 1488,0 \\
\hline
\end{tabular}

Источник: Регионы России. Сочиально-экономические показатели - 2020 2. https://gks.ru/bgd/regl/b20_14p/ Main.htm

Примечание: $Р K^{*}$ - Республика Крым; СВС-2. Севастополь 
Численность персонала, занятого научными исследованиями и разработками, в ЮФО снизилась на $7,5 \%$, в то время как в СКФО наблюдался относительный прирост данного показателя $19,3 \%$ (см. таблицу 4).

Таблииа 4

\begin{tabular}{|l|c|c|c|c|c|c|c|c|c|c|c|c|}
\hline & 2005 & 2010 & 2011 & 2012 & 2013 & 2014 & 2015 & 2016 & 2017 & 2018 & 2019 & $2019 / 2000, \%$ \\
\hline ЮФО & 28875 & 28109 & 27738 & 23964 & 24263 & 27825 & 30130 & 28011 & 26922 & 26431 & 26713 & 92,51 \\
\hline РА & 163 & 330 & 357 & 316 & 326 & 305 & 279 & 282 & 283 & 271 & 276 & 169,33 \\
\hline РК & 221 & 203 & 190 & 181 & 183 & 213 & 175 & 184 & 158 & 147 & 149 & 67,42 \\
\hline РК* & 0 & 0 & 0 & 0 & 0 & 1550 & 1676 & 2096 & 2113 & 1995 & 2045 & - \\
\hline КК & 7000 & 6256 & 6059 & 6504 & 6872 & 7585 & 9265 & 7532 & 6916 & 6918 & 6752 & 96,46 \\
\hline АО & 1621 & 917 & 966 & 1014 & 1083 & 904 & 933 & 692 & 653 & 637 & 830 & 51,20 \\
\hline ВО & 4157 & 4001 & 3988 & 3639 & 3568 & 3732 & 3958 & 4026 & 3869 & 3695 & 3582 & 86,17 \\
\hline РО & 15713 & 16402 & 16178 & 12310 & 12231 & 12622 & 12556 & 12102 & 11846 & 11720 & 11974 & 76,20 \\
\hline г. СВС & 0 & 0 & 0 & 0 & 0 & 914 & 1288 & 1097 & 1084 & 1048 & 1105 & - \\
\hline СКФО & 5655 & 6053 & 8585 & 7188 & 6330 & 6628 & 7521 & 7655 & 7237 & 7024 & 6745 & 119,27 \\
\hline РД & 1827 & 1642 & 1628 & 1606 & 1561 & 1548 & 1689 & 1997 & 1693 & 1567 & 1442 & 78,93 \\
\hline РИ & 23 & 95 & 112 & 114 & 114 & 130 & 346 & 326 & 244 & 175 & 176 & 765,22 \\
\hline КБР & 682 & 677 & 704 & 746 & 783 & 744 & 894 & 1122 & 1050 & 1039 & 1101 & 161,44 \\
\hline КЧР & 569 & 491 & 506 & 505 & 508 & 561 & 586 & 581 & 589 & 584 & 623 & 109,49 \\
\hline РСО & 549 & 643 & 685 & 648 & 650 & 669 & 654 & 612 & 547 & 577 & 563 & 102,55 \\
\hline ЧР & 271 & 412 & 639 & 592 & 646 & 593 & 561 & 480 & 480 & 404 & 349 & 128,78 \\
\hline
\end{tabular}

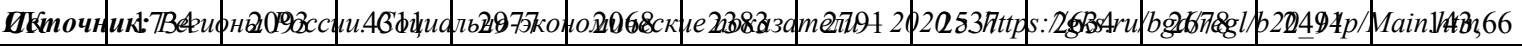
Примечание: РК*- Республика Крым; СВС-2. Севастополь.

Регрессионная модель оценки влияния инновационных детерминант на динамику экономического роста российских субъектов в СКФО имеет следующий вид:

$$
y=-5,78+0,42 X_{1}+0,62 X_{2}+1,41 X_{3}+\varepsilon
$$

где

Y - валовый региональный продукт СКФО, млн. руб.

$\mathrm{X}_{1}$ - количество организаций, выполнявших исследования и разработки, ед. (СКФО);

$\mathrm{X}_{2}$ - затраты на технологические инновации, млн. руб. (СКФО);

$\mathrm{X}_{3}$ - численность персонала, занятого научными исследованиями и разработками (человек) (СКФО).

Интегрированный результат регрессионной оценки и дисперсионного анализа влияния инновационных факторов на экономический рост двух макрорегионов (СКФО и ЮФО) представлен в таблице 5 .

\begin{tabular}{|c|c|c|c|c|c|c|c|c|c|c|}
\hline \multicolumn{11}{|c|}{ Регрессионная статистика } \\
\hline & & & & & & \multicolumn{3}{|c|}{ СКФО } & \multicolumn{2}{|l|}{ ЮФО } \\
\hline \multicolumn{6}{|c|}{ Множественный R } & \multicolumn{3}{|c|}{0,976} & \multicolumn{2}{|l|}{0,984} \\
\hline \multicolumn{6}{|l|}{ R-квадрат } & \multicolumn{3}{|c|}{0,952} & \multicolumn{2}{|l|}{0,968} \\
\hline \multicolumn{6}{|c|}{ Нормированный R-квадрат } & \multicolumn{3}{|c|}{0,945} & \multicolumn{2}{|l|}{0,962} \\
\hline \multicolumn{6}{|c|}{ Стандартная ошибка } & \multicolumn{3}{|c|}{0,308} & \multicolumn{2}{|l|}{0,251} \\
\hline Наблюдени & & & & & & \multicolumn{3}{|c|}{24} & \multicolumn{2}{|l|}{23} \\
\hline \multicolumn{11}{|c|}{ Дисперсионный анализ } \\
\hline & \multicolumn{2}{|c|}{$d f$} & \multicolumn{2}{|c|}{ SS } & \multicolumn{2}{|c|}{$M S$} & \multicolumn{2}{|c|}{$F$} & \multicolumn{2}{|c|}{ Значимость $F$} \\
\hline & СКФО & ЮФО & СКФО & ЮФО & СКФО & ЮФО & СКФО & ЮФО & СКФО & ЮФО \\
\hline Регрессия & 3 & 3 & 35,68 & 37,89 & 11,89 & 12,63 & 189,22 & 133,53 & $2,52 \mathrm{E}-14$ & $2,14 \mathrm{E}-13$ \\
\hline Остаток & 19 & 20 & 1,19 & 1,89 & 0,06 & 0,094 & & & & \\
\hline Итого & 22 & 23 & 36,87 & 39,78 & & & & & & \\
\hline
\end{tabular}


3. Выводы. Методом наименьших квадратов была проведена оценка параметров уравнения с помощью инструмента «Регрессия» в Microsoft Excel. Полученные результаты регрессионного анализа (таблица 5) отражают высокое качество линейной модели множественной регрессии. Коэффициент детерминации показывает, что построенная регрессия объясняет 95,2 \% (СКФО) 96,8 \% (ЮФО) вариации экономического роста в СКФО и ЮФО.

Критерий p-value составил 2,52E-14 (СКФО) и 2,14Е-13 (ЮФО), что меньше, чем $\alpha=0,01$. Полученный результат означает, что с вероятностью $99 \%$ отвергается нулевая гипотеза о неадекватности уравнения регрессии.

Согласно полученной спецификации наибольшее влияние на экономический рост СКФО оказывает компонента $X_{3}$ - численность персонала, занятого научными исследованиями и разработками (человек) (СКФО). Далее по силе воздействия на динамику экономического роста макрорегиона следуют факторы $\mathrm{X}_{2}$ - затраты на технологические инновации, млн. руб.

Литература

1. Abramovitz, M. (1956). Resource and output trends in the U.S. since 1870. American Economic Review (Papers and proceedings). 46 (2), 5-23.

2. Abramovitz. M. (1993). The search for the sources of growth: Areas of ignorance, old and new. Journal of Economic History. 53(2). 217-243.

3. Baldwin, John, Desmond Beckstead and Guy Gellatly (2004), Canada's Expenditures on Knowledge Capital, Statistics Canada.

4. Barro. R. J. \& Sala-I-Martin. X. (1999). Economic Growth. Cambridge, MA: The MIT Press.

5. Boskin, M.J. \& Lau, L.J. (1996). Contnbutions of R\&D to economic growth. In S. Smith \& C. Barfield (Eds.), Technology, R\&D and the economy. Washington DC: The Brookings Institute and the American Enterprise Institute).

6. Denison. E. F. (1962). The Sources of Economic Growth in the United States (Supplementary Paper). The Research and Policy Committee of the Committee for Economic Development.

7. Griliches, Z. (1994). Productivity. R\&D and the data constraint. American Economic Review. 84. 1-23.

8. Griliches. Z. (1990). Patent statistics as economic indicators: A survey. Journal of Economic Literature. 28 (4), 1661-1707.

9. Hill (Hill, T.M. (1991) Research and development and regional productivity (CPRP Working Paper 9104.

10. Hunt, D. (1989). Economic theories of development: An analysis of competing paradigms. Sav-age, MD: Barnes \&. Noble Books., cmp. 33-34.

11. In Z. Griliches (Ed.) R\&D. Patents and Productivity, (pp. 27-55). University of Chicago Press.

12. Kamin, J.Y, I. Bijaoui and R. Horesh (1982), Some Determinants of Cost Distributions in the Process of Technological Innovation, Research Policy, vol. 11, pp.83-94.

13. Pakes \& Griliches, Pakes. A. \& Griliches. Z. (1984). Patents and R\&D at the firm level: A first look, pp.55-27.

14. Romer, P.M. (1986). Increasing returns and long-run growth. Journal of Political Economy. 94, (5), $1002-$ 1037

15. Romer. P. M. (1990). Endogenous technological change. The Journal of Political Economy, 98, (5), Part 2: The Problem of Development: A conference of the Institute for the Study of Free Enterprise Systems. S 71 . S102.

16. Schumpeter. J. (1942). Capitalism. Socialism and Democracy. (2nd ed.) London: George Allen \& Unwin. 17. Smith. A. 1937. «The Wealth of Nations». New York: Random House.

18. Solow, R.M. (1956). A contribution to the theory of economic grow th. Quarterly Journal of Economics. 70, 65-94.

19. Solow. R. M. (1957). Technological change and the aggregate production function. Review of Economics and Statistics. 39. 312-320.

20. Ахмедуев А.ШІ. Проблемы и стратегические приоритеты социально-экономического развития субъектов Северо-Кавказского федерального округа России // Региональная экономика: теория и практика. 2015. № 34 (409). С. 14-29.

21. Гичиев Н.С. Экономический рост макрорегиона: эконометрическая модель, сценарии и прогнозы // c. $177-188$.

22. Гичиев Н.С. Экономический рост на основе международной интеграчии: внешняя торговля и валютный курс // Региональные проблемы преобразования экономики. 2014. № 9 (47). С. 259-272.

23. Кутаев Ш.К., Сагидов Ю.Н. Современное состояние и проблемы развития промышиленности региона // Региональные проблемы преобразования экономики. 2014. № 6 (44). С. 62-66.

24. Петросяни В.З., Дохолян С.В., Петросяни Д.В., Баширова А.А. Стратегия регионального развития 8 условиях инноваиионных преобразований экономики. Москва, 2011.

25. Региональные проблемы преобразования экономики. 2017. № 12 (86). С. 177-188.

26. Статистические сборники. Регионы России. Соииально-экономические показатели - 2020 2. https:// gks.ru/bgd/regl/b20_14p/Main.htm

References:

1. Abramovitz, M. (1956). Resource and output trends in the U.S. since 1870. American Economic Review (Papers and proceedings). 46 (2), 5-23. 
2. Abramovitz. M. (1993). The search for the sources of growth: Areas of ignorance, old and new. Journal of Economic History. 53(2). 217-243.

3. Baldwin, John, Desmond Beckstead and Guy Gellatly (2004), Canada's Expenditures on Knowledge Capital, Statistics Canada.

4. Barro. R. J. \& Sala-I-Martin. X. (1999). Economic Growth. Cambridge, MA: The MIT Press.

5. Boskin, M.J. \& Lau, L.J. (1996). Contnbutions of R\&D to economic growth. In S. Smith \& C. Barfield (Eds.), Technology, R\&D and the economy. Washington DC: The Brookings Institute and the American Enterprise Institute).

6. Denison. E. F. (1962). The Sources of Economic Growth in the United States (Supplementary Paper). The Research and Policy Committee of the Committee for Economic Development.

7. Griliches, Z. (1994). Productivity. R\&D and the data constraint. American Economic Review. 84. 1-23.

8. Griliches. Z. (1990). Patent statistics as economic indicators: A survey. Journal of Economic Literature. 28 (4), 1661-1707.

9. Hill (Hill, T.M. (1991) Research and development and regional productivity (CPRP Working Paper 9104.

10. Hunt, D. (1989). Economic theories of development: An analysis of competing paradigms. Sav-age, MD: Barnes \&. Noble Books., str. 33-34.

11. In Z. Griliches (Ed.) R\&D. Patents and Productivity, (pp. 27-55). University of Chicago Press.

12. Kamin, J.Y, I. Bijaoui and R. Horesh (1982), Some Determinants of Cost Distributions in the Process of Technological Innovation, Research Policy, vol. 11, pp.83-94.

13. Pakes \& Griliches, Pakes. A. \& Griliches. Z. (1984). Patents and R\&D at the firm level: A first look, pp.5527.

14. Romer, P.M. (1986). Increasing returns and long-run growth. Journal of Political Economy. 94, (5), $1002-$ 1037

15. Romer. P. M. (1990). Endogenous technological change. The Journal of Political Economy, 98, (5), Part 2: The Problem of Development: A conference of the Institute for the Study of Free Enterprise Systems. S 71 . S102.

16. Schumpeter. J. (1942). Capitalism. Socialism and Democracy. (2nd ed.) London: George Allen \& Unwin. 17. Smith. A. 1937. "The Wealth of Nations». New York: Random House.

18. Solow, R.M. (1956). A contribution to the theory of economic grow th. Quarterly Journal of Economics. 70 , 65-94.

19. Solow. R. M. (1957). Technological change and the aggregate production function. Review of Economics and Statistics. 39. 312-320.

20. Ahmeduev A.SH. Problemy i strategicheskie prioritety social'no-ekonomicheskogo razvitiya subëktov Severo-Kavkazskogo federal'nogo okruga Rossii // Regional'naya ekonomika: teoriya i praktika. 2015. № 34 (409). S. 14-29.

21. Gichiev N.S. Ekonomicheskij rost makroregiona: ekonometricheskaya model', scenarii i prognozy // s. 177 188.

22. Gichiev N.S. Ekonomicheskij rost na osnove mezhdunarodnoj integracii: vneshnyaya torgovlya $i$ valyutnyj kurs // Regional'nye problemy preobrazovaniya ekonomiki. 2014. № 9 (47). S. 259-272.

23. Kutaev SH.K., Sagidov YU.N. Sovremennoe sostoyanie i problemy razvitiya promyshlennosti regiona // Regional'nye problemy preobrazovaniya ekonomiki. 2014. № 6 (44). S. 62-66.

24. Petrosyanc V.Z., Doholyan S.V., Petrosyanc D.V., Bashirova A.A. Strategiya regional'nogo razvitiya $v$ usloviyah innovacionny preobrazovanij ekonomiki. Moskva, 2011.

25. Regional'nye problemy preobrazovaniya ekonomiki. 2017. № 12 (86). S. 177-188.

26. Statisticheskie sborniki. Regiony Rossii. Social'no-ekonomicheskie pokazateli-2020 g. https://gks.ru/bgd/ $\mathrm{regl} / \mathrm{b} 20 \_14 \mathrm{p} /$ Main.htm 